\title{
Controle de Fusarium oxysporum f.sp. phaseoli in vitro e em sementes, e promoção do crescimento inicial do feijoeiro comum por Trichoderma harzianum
}

\author{
Daniel D.C. Carvalho ${ }^{1}$, Sueli C.M. Mello ${ }^{2}$, Murillo Lobo Júnior ${ }^{3} \&$ Mayara C. Silva $^{2}$ \\ ${ }^{1}$ Departamento de Fitopatologia, Universidade de Brasília, 70910-900, Brasília, DF, Brasil; ${ }^{2}$ Embrapa Recursos Genéticos e \\ Biotecnologia, 70770-900, Brasília, DF, Brasil; ${ }^{3}$ Embrapa Arroz e Feijão, 75375-000, Santo Antônio de Goiás, GO, Brasil
}

Autor para correspondência: Sueli C.M. Mello, e-mail: smello@cenargen.embrapa.br

\begin{abstract}
RESUMO
Este trabalho objetivou avaliar seis isolados de Trichoderma harzianum no controle de Fusarium oxysporum f.sp. phaseoli em sementes, e seu efeito no crescimento inicial do feijoeiro comum. Os isolados foram inicialmente confrontados in vitro com o patógeno em testes de cultura pareada e antibiose a $25^{\circ} \mathrm{C}$. Sementes sadias e artificialmente infectadas pelo patógeno foram microbiolizadas com $2 \mathrm{~mL}$ de suspensões dos antagonistas $\left(2,5 \times 10^{8}\right.$ conídios $\left.\mathrm{mL}^{-1}\right)$ para cada $100 \mathrm{~g}$ de sementes, em rolo de papel germtest a 20 e $25^{\circ} \mathrm{C}$. Os percentuais de incidência do patógeno e de plântulas normais foram avaliados aos sete e nove dias, respectivamente. Em casa de vegetação, os isolados foram aplicados a $5 \times 10^{9}$ conídios $500 \mathrm{~g}^{-1}$ de substrato autoclavado, com avaliação do comprimento das raízes e parte aérea das plantas 11 dias após o semeio (12 plantas tratamento ${ }^{-1}$ ). Todos os isolados apresentaram antagonismo in vitro contra o patógeno. Os isolados CEN202, CEN234, CEN238, CEN240 foram superiores à testemunha no controle de $F$. oxysporum em sementes, reduzindo entre 35 e $51 \%$ da incidência do patógeno e proporcionando entre 73 e $81 \%$ de plântulas normais. O comprimento total das plantas com tratamento CEN239 (37,43 cm) foi superior aos demais, cujo comprimento variou entre 27,84 e 33,95 cm.

Palavras-chave: Phaseolus vulgaris, controle biológico, patologia de sementes, supressão de crescimento.
\end{abstract}

\begin{abstract}
Control of Fusarium oxysporum f.sp phaseoli in vitro and on seeds and growth promotion of common bean in early stages by Trichoderma harzianum

The objective of this study was to evaluate the antagonistic capacity of six isolates of Trichoderma harzianum against Fusarium oxysporum f.sp. phaseoli on infected seeds and its effect on the early stages of growth in bean plants. The isolates were also evaluated in dual culture assays and under in vitro antibiosis at $25^{\circ} \mathrm{C}$. Healthy and infected seeds were treated with $2 \mathrm{~mL} 100 \mathrm{~g}^{-1}$ seeds of the antagonist suspensions $\left(2.5 \times 10^{8}\right.$ conidia $\left.\mathrm{mL}^{-1}\right)$ for healthy evaluation using blotter method at 20 and $25^{\circ} \mathrm{C}$. The percentages of pathogen incidence and normal seedlings were evaluated at seven and nine days, respectively. The isolates were applied at $5 \times 10^{9}$ conidia $500 \mathrm{~g}^{-1}$ of sterilized substrate in greenhouse. After 11 days, roots and shoots of the bean plants were measured (12 plants treatment $\left.{ }^{-1}\right)$. Every isolate of $T$. harzianum presented in vitro antagonism against the pathogen. The strains CEN202, CEN234, CEN238 and CEN240 offered better control of $F$. oxysporum on seeds than the positive check, causing a reduction between 35 and $51 \%$ in pathogen incidence and $73-81 \%$ of normal seedling emergence. The total length of the plants treated with CEN239 $(37.43 \mathrm{~cm})$ was longer than the other treatments, with length varying between 27.84 and $33.95 \mathrm{~cm}$.
\end{abstract}

Key words: Phaseolus vulgaris, biocontrol, seed pathology, growth suppression.

\section{INTRODUÇÃO}

As sementes são importantes veículos de agentes fitopatogênicos, os quais podem provocar redução, tanto na germinação quanto no vigor das plântulas. Invariavelmente, sementes infectadas ou infestadas por patógenos originam focos primários de infecção (Machado et al., 2001). Doenças de importância econômica para a cultura do feijoeiro comum (Phaseolus vulgaris L.) são causadas por patógenos transmitidos pelas sementes, dentre eles o fungo Fusarium oxysporum Schlecht. f.sp. phaseoli Kendrick \& Snyder, causador da murcha de fusário do feijoeiro (Paula Júnior et al.,
2008). As estruturas do patógeno presentes nas sementes permanecem viáveis durante o período de armazenamento e constituem o inóculo primário para o desenvolvimento de epidemias (Silva et al., 2008).

O uso de sementes tratadas com agentes de biocontrole é uma das recomendações para conter a transmissão de doenças via sementes, além de contribuir para uma maior densidade de plantas na lavoura (Corrêa et al., 2008). Por outro lado, o tratamento de sementes com fungicidas sintéticos tem sido questionado devido ao uso abusivo desses produtos na agricultura, por onerar os custos de produção e, principalmente, por contaminar o meio ambiente (Vinale et al., 2008).

Tropical Plant Pathology 36 (1) January - February 2011 
Espécies de Trichoderma são potenciais antagonistas de diversos fungos fitopatogênicos. São vários os mecanismos de ação utilizados por esses fungos, dentre os quais, destacam-se a produção de metabólitos e enzimas com propriedades antifúngicas, o hiperparasitismo e a competição por nutrientes (Harman et al., 2004). Como vantagem adicional, esses microrganismos são referidos como atóxicos ao homem e animais (Mertz et al., 2009) e como simbiontes avirulentos associados às plantas (Harman et al., 2004). Portanto, representam uma possível alternativa para controle de patógenos de sementes.

Adicionalmente, alguns isolados de Trichoderma têm sido referidos como estimuladores do crescimento vegetal, pela habilidade que possuem na solubilização de fosfato e outros minerais, colocando-os disponíveis para as plantas, e também pela produção de análogos de auxinas (Harman, 2000; Vinale et al., 2008). Tais substâncias apresentam propriedades de induzir a elongação celular nos vegetais superiores (Taiz \& Zeiger, 2006). Também é conhecida a ação dos compostos sideróforos - moléculas de baixo peso molecular, quelante de íons férricos e sintetizados por vários microrganismos, dentre os quais Trichoderma que resulta na solubilização do ferro presente no solo, em benefício das plantas. A produção de sideróforos coloca o microrganismo em vantagem sobre seus competidores na competição pelo ferro disponível no ambiente (Benítez et al., 2004). Este trabalho teve o objetivo de avaliar o controle de $F$. oxysporum f.sp. phaseoli in vitro e em sementes e a promoção do crescimento inicial de plantas de feijoeiro comum por isolados de Trichoderma harzianum.

\section{MATERIAL E MÉTODOS}

Os isolados de T. harzianum (CEN202, CEN234, CEN238, CEN239, CEN240 e CEN241) e F. oxysporum f.sp. phaseoli (C-03-01) utilizados neste trabalho pertencem à Coleção de Microrganismos para Controle Biológico de Fitopatógenos da Embrapa Recursos Genéticos e Biotecnologia, em Brasília, DF, onde foram realizados os ensaios in vitro. A seleção dos seis isolados do antagonista para este estudo foi baseada em resultados anteriores, obtidos no controle de outros patógenos do solo por Ávila et al. (2005). As culturas foram reativadas em meio batatadextrose-ágar (BDA).

\section{Avaliação do antagonismo in vitro de $T$. harzianum em cultura pareada}

Para avaliar o antagonismo dos isolados de $T$. harzianum contra o patógeno $F$. oxysporum f.sp. phaseoli, utilizou-se o método de cultura pareada descrito por Dennis \&Webster(1971), sendo que o patógeno foi repicado três dias antes do antagonista, opostamente em cada placa. As placas foram submetidas a temperatura de $25^{\circ} \mathrm{C}$ em BOD Fanem 347 , com fotoperíodo de $12 \mathrm{~h}$. As avaliações consistiram nas medições do diâmetro das colônias do patógeno com régua milimétrica e agrupamento dos isolados em classes, de acordo com escala descrita por Bell et al. (1982), aos sete e aos 13 dias após repicagem dos antagonistas, respectivamente. O experimento foi conduzido duas vezes, em delineamento inteiramente casualizado (DIC), com quatro repetições para cada isolado de Trichoderma.

\section{Ação de metabólitos voláteis e não voláteis dos isolados} de T. harzianum sobre $F$. oxysporum f.sp. phaseoli

Após três dias de crescimento de $F$. oxysporum em BDA a $25^{\circ} \mathrm{C}$ e fotoperíodo de $12 \mathrm{~h}$, bases de outras placas de Petri de tamanho correspondente, contendo meio BDA solidificado, receberam no seu centro um disco de ágar contendo micélio dos antagonistas. As bases das placas contendo o antagonista recém colocado e o patógeno (com três dias de crescimento) foram sobrepostas e unidas com filme plástico transparente. As placas foram incubadas nas condições mencionadas, de forma que as bases superiores fossem aquelas que continham o patógeno. Após cinco dias, quando a colônia testemunha (base correspondente ao antagonista contendo apenas BDA solidificado) encontravase totalmente colonizada, mediu-se o diâmetro das colônias de $F$. oxysporum. Os valores médios de percentagens de inibição foram obtidos em relação ao crescimento da testemunha. Considerou-se $100 \%$ de crescimento a área final ocupada pela testemunha menos a área inicial (patógeno com três dias de crescimento).

Para verificar a ação de metabólitos não voláteis, filtrados das culturas de Trichoderma foram incorporados ao meio, conforme descrito por Mello et al. (2007). Cinco discos $(5 \mathrm{~mm})$ contendo micélio de $T$. harzianum foram transferidos para frascos Erlenmeyer $(500 \mathrm{~mL})$, contendo $250 \mathrm{~mL}$ de meio BD (batata-dextrose). Após cinco dias de cultivo em agitador orbital (Lab line Instruments, Inc., modelo 60160) a $250 \mathrm{rpm}$ e temperatura de $25^{\circ} \mathrm{C}$, em ausência de luz, as culturas foram filtradas, com auxílio de bomba a vácuo. Cada isolado passou por três filtrações, com 1,2 e 3 papéis de filtro, respectivamente. A parte líquida foi esterilizada por filtração (filtro Millipore $0,45 \mu \mathrm{m}$ ). Cinco mililitros do filtrado de cada isolado foi acrescido a $15 \mathrm{~mL}$ de BDA fundente contendo ágar a $28 \%$, em placa de Petri. Após solidificação do meio, um disco de ágar (5 mm de diâmetro), contendo micélio do patógeno, foi depositado sobre o meio. Para a testemunha, adicionaramse $5 \mathrm{~mL}$ de água destilada esterilizada ao BDA fundente. As placas foram incubadas a $25^{\circ} \mathrm{C}$ e fotoperíodo de $12 \mathrm{~h}$, até completa colonização do meio pelo patógeno, nas placas da testemunha, que se deu no sétimo dia. Tomaram-se, então, as medidas de diâmetro das colônias do patógeno. Os valores obtidos foram convertidos em percentagem, como no item anterior. Os experimentos com metabólitos voláteis e não voláteis foram conduzidos duas vezes, em DIC, com quatro repetições para cada isolado de Trichoderma.

\section{Multiplicação de inóculo de T. harzianum}

Para os testes seguintes, conduzidos no Laboratório de Qualidade e Sanidade de Sementes da Embrapa Arroz 
e Feijão, o inóculo de T. harzianum foi multiplicado em substrato sólido. Discos de ágar contendo micélio do antagonista foram transferidos para frascos Erlenmeyer (250 $\mathrm{mL})$, contendo arroz parboilizado $\left(15 \mathrm{~g}_{\text {frasco }}{ }^{-1}\right)$, previamente umedecido com água destilada $\left(60 \% \mathrm{p} \mathrm{v}^{-1}\right)$ e autoclavado. Os frascos foram mantidos em BOD a $25^{\circ} \mathrm{C}$, com fotoperíodo de 12 horas, durante seis dias. Os esporos foram coletados por meio de filtração em gaze esterilizada, de uma suspensão obtida pela adição de água destilada esterilizada ao substrato. As concentrações de esporos foram determinadas com o auxílio de câmara de Neubauer, sob lente de 40x.

\section{Infecção e infestação de sementes com $F$. oxysporum}

Para obtenção de sementes infectadas e infestadas por F. oxysporum f.sp. phaseoli, empregou-se a técnica de restrição hídrica utilizando-se meio BDA + Manitol a $-1,0 \mathrm{MPa}$ (Costa et al., 2003). Após seis dias de cultivo do patógeno nas placas de $15 \mathrm{~cm}$ (seis discos/ placa) e constatada a colonização total da superfície do meio, as placas receberam sementes de feijão 'Jalo Precoce'. Essas sementes foram previamente desinfestadas ( $1 \mathrm{~min}$ com hipoclorito de sódio 1\%), lavadas duas vezes por 1 minuto em água destilada esterilizada e submetidas à secagem em câmara de fluxo laminar (20 min). As sementes assim preparadas e distribuídas na superfície do meio colonizado foram, então, incubadas por cinco dias.

\section{Análise sanitária das sementes tratadas com $T$. harzianum}

Após o procedimento anterior, realizou-se o tratamento das sementes com T. harzianum, empregando-se os seis isolados descritos anteriormente, mais um isolado comercial da mesma espécie (Trichodermil ${ }^{\circledR} \mathrm{SC}$, Itaforte Bioprodutos, Itapetininga, SP). Utilizaram-se $2 \mathrm{~mL}$ de suspensão a $2,5 \times 10^{8}$ conídios $\mathrm{mL}^{-1}$ para cada $100 \mathrm{~g}$ de sementes. Em seguida, foi realizada a análise de sanidade de sementes conforme Brasil (2009). Neste teste, cada tratamento constou de 200 sementes, divididas em quatro repetições. Em cada uma, 50 sementes foram distribuídas uniformemente sobre duas folhas de papel germitest $(44,0$ $\mathrm{x} 34,0 \mathrm{~cm}$ ), umedecidas com água destilada e cobertas com uma terceira folha umedecida para fechamento do rolo de papel. Os rolos de papel contendo as sementes foram colocados dentro de saco de polietileno preto e encaminhados para sala de incubação $\left(20^{\circ} \mathrm{C}\right.$ e umidade relativa de $98 \%$ ), onde permaneceram pelo período de sete dias. A verificação da incidência do patógeno consistiu na observação, ao microscópio estereoscópio (Zeiss Stemi DV4), de: micélio aéreo, monofiálides, microconídios e macroconídios típicos de $F$. oxysporum ao redor das sementes e plântulas, de acordo com Brasil (2009). A confirmação da espécie ocorreu mediante confecção de lâminas microscópicas semi-permanentes e análise destas sob lente de aumento 40x (microscópio ótico Nikon Eclipse 55i). Como controle negativo e positivo, empregaram-se sementes tratadas com fungicida químico Vitavax ${ }^{\circledR}$-Thiram a $300 \mathrm{~mL} 100 \mathrm{~kg}^{-1}$ sementes (200 $\mathrm{g} \mathrm{L}^{-1}$ de carboxina; 200 $\mathrm{g} \mathrm{L}^{-1}$ de thiram) e sementes não tratadas, respectivamente. Utilizou-se o DIC, com quatro repetições de 50 sementes (rolo de papel), por tratamento.

\section{Testes de germinação e vigor de sementes}

O teste de sanidade foi acompanhado por dois testes de germinação, com sementes de feijão comum 'Jalo Precoce' infectadas e não infectadas com o patógeno. Em ambos os casos, as sementes foram submetidas ao tratamento com os isolados de T. harzianum, na mesma dosagem empregada para o teste de sanidade. O experimento foi conduzido em DIC, com quatro repetições de 50 sementes por tratamento. As sementes organizadas em rolos, como no ensaio anterior, foram acondicionadas em germinador De Leo à temperatura de $25^{\circ} \mathrm{C}$, onde permaneceram por nove dias. $\mathrm{Na}$ avaliação, foram estimadas as porcentagens de plântulas normais, segundo as Regras para Análise de Sementes (Brasil, 2009).

\section{Efeito de T. harzianum no crescimento de plantas de feijoeiro comum em casa de vegetação}

Vasos de $500 \mathrm{~g}$ de capacidade, contendo o substrato comercial autoclavado Plantmax ${ }^{\circledR}$, receberam um volume de $50 \mathrm{~mL} /$ vaso de suspensão de esporos $\left(10^{8}\right.$ conídios $\mathrm{mL}^{-1}$ ) de T. harzianum, perfazendo $5 \times 10^{9}$ conídios 500 $\mathrm{g}^{-1}$ de substrato. Imediatamente após, foram semeadas cinco sementes de feijão 'Jalo Precoce' por vaso. Após 11 dias, procederam-se as avaliações, tomando-se as medidas de comprimento de raízes e parte aérea de 12 plantas por tratamento. Com o objetivo de verificar se um tratamento adicional ao tratamento de substrato com Trichoderma era capaz de promover ainda mais o crescimento das plantas, outro experimento foi instalado com os mesmos tratamentos. Entretanto, as sementes deste experimento foram tratadas com promotor de crescimento Rhal S1 ${ }^{\circledR}(18 \%$ de ácidos húmico $+1,5 \%$ de ácidos fúlvicos; Rhal Produtos Agropecuários, Criciúma, SC), na dosagem de $600 \mathrm{~mL}$ do produto comercial $100 \mathrm{~kg}^{-1}$ sementes. Os experimentos foram dispostos em DIC com quatro repetições (4 vasos) para cada isolado do antagonista. Como controles para os dois experimentos, empregaram-se sementes semeadas em substrato autoclavado não tratado com T. harzianum. As sementes da Testemunha do primeiro experimento não foram tratadas com Rhal S1 ${ }^{\circledR}$ (Testemunha absoluta). Todos os resultados foram submetidos à análise de variância (ANAVA) e ao teste de Scott-Knott $(\mathrm{P} \leq 0,05)$, com o auxílio do programa Sisvar (Ferreira, 2000).

\section{RESULTADOS E DISCUSSÃO}

\section{Avaliação do antagonismo in vitro de $T$. harzianum em cultura pareada}

Os valores médios de crescimento de colônias do patógeno, em relação à testemunha, verificado aos sete dias de cultivo, foram menores com os isolados CEN234, 
CEN238, CEN239 e CEN241 (Tabela 1). Entretanto, aos 13 dias de cultivo pareado, os isolados CEN238, CEN239 e CEN241 foram os que apresentaram colonização total sobre o patógeno. Assim, estes foram agrupados na classe 1, de acordo com escala de Bell et al. (1982). Após o contato entre colônias de antagonista e patógeno, esses três isolados continuaram em crescimento, invadindo totalmente a colônia do patógeno, sobre as quais produziram conídios. Todos os demais isolados também revelaram bom potencial contra o patógeno testado e foram agrupados na classe 2 , da mesma escala (Tabela 1). A redução do crescimento de $F$. oxysporum f.sp. phaseoli pode ser atribuída à competição por espaço e por nutrientes presentes no meio de cultura e/ou ao hiperparasitismo (Vinale et al., 2008).

\section{Ação de metabólitos voláteis e não voláteis dos isolados de $T$. harzianum sobre $F$. oxysporum}

Quanto à produção de metabólitos secundários voláteis, todos os isolados de T. harzianum testados exibiram ação antifúngica e não diferiram entre si (Tabela 2). Os valores médios de porcentagem de inibição verificaramse próximo a de $50 \%$. Já no experimento para verificação do efeito de metabólitos não voláteis, o isolado CEN239 foi o único que se distinguiu dos demais, não diferindo da testemunha. Pode-se inferir, portanto, que não houve ação por metabólitos tóxicos biologicamente difusíveis no meio de cultivo que recebeu filtrado de colônia deste isolado. De fato, a capacidade para produzir metabólitos tóxicos com efeito fungicida ou fungistático pode variar entre isolados da mesma espécie (Martins-Corder \& Melo, 1998). Embora Dubey et al. (2007) tenham constatado em T. harzianum a capacidade de inibir o crescimento de $F$. oxysporum f.sp. ciceris pela produção de metabólitos não voláteis, os melhores resultados foram proporcionados pela produção de metabólitos voláteis (Tabela 2).

\section{Análise sanitária das sementes tratadas com Trichoderma harzianum e testes de germinação e vigor}

O fungicida Vitavax ${ }^{\circledR}$-Thiram foi o melhor tratamento no controle de $F$. oxysporum f.sp. phaseoli nas sementes

TABELA 1 - Crescimento de Fusarium oxysporum f.sp. phaseoli em cultivo pareado com isolados de Trichoderma harzianum e classificação dos isolados quanto ao antagonismo, segundo escala de Bell et al. (1982) após sete e 13 dias de incubação, respectivamente

\begin{tabular}{lcc}
\hline \hline $\begin{array}{l}\text { Isolado de } \boldsymbol{T} \text { harzianum } \\
\text { CEN202 }\end{array}$ & $\begin{array}{c}\text { Diâmetro médio das colônias de } \boldsymbol{F} \text {. oxysporum } \\
(\mathbf{m m}) \text { aos } \mathbf{7} \text { dias }^{(\mathbf{1})}\end{array}$ & $\begin{array}{c}\text { Classificação dos isolados de Trichoderma } \\
\text { aos 13 dias }^{(\mathbf{2})}\end{array}$ \\
\hline CEN234 & $41,25 \mathrm{~b}$ & $1,9^{(\mathrm{ns})}$ \\
CEN238 & $36,50 \mathrm{a}$ & 1,9 \\
CEN239 & $36,75 \mathrm{a}$ & 1,4 \\
CEN240 & $36,75 \mathrm{a}$ & 1,4 \\
CEN241 & $40,50 \mathrm{~b}$ & 1,8 \\
Coeficiente de variação & $36,25 \mathrm{a}$ & 1,2 \\
\hline
\end{tabular}

${ }^{(1)}$ Valores seguidos pela mesma letra, na coluna, não diferem estatisticamente, segundo o teste de Scott-Knott $(\mathrm{P} \leq 0,05)$; ${ }^{(2)}$ Classe 1: Trichoderma cresce sobre o patógeno e ocupa toda a superfície do meio; Classe 2: Trichoderma cresce sobre pelo menos 2/3 da superfície do meio; Classe 3 : Trichoderma ocupam aproximadamente metade da superfície do meio; Classe 4: Trichoderma cresce sobre 1/3 da superfície do meio; Classe 5 : Trichoderma não cresce e o patógeno ocupa toda a superfície da placa; ${ }^{(n)}$ Médias não significativas, segundo o teste de Scott-Knott $(\mathrm{P} \leq 0,05)$.

TABELA 2 - Efeito inibidor de metabólitos voláteis e não voláteis de Trichoderma harzianum sobre o crescimento de Fusarium oxysporum f.sp. phaseoli

\begin{tabular}{|c|c|c|}
\hline \multirow{2}{*}{$\begin{array}{l}\text { Isolado de } T \text {. } \\
\text { harzianum }\end{array}$} & \multicolumn{2}{|c|}{ Crescimento de colônias de $F$. oxysporum sob o efeito de metabólitos de $T$. harzianum ${ }^{(1)}$} \\
\hline & Metabólitos voláteis $(\%)^{(2)}$ & Metabólitos não voláteis (\%) ${ }^{(2)}$ \\
\hline CEN202 & $47,91 \mathrm{aA}$ & $86,49 \mathrm{aB}$ \\
\hline CEN234 & $48,02 \mathrm{aA}$ & $86,06 \mathrm{aB}$ \\
\hline CEN238 & $51,18 \mathrm{aA}$ & $86,26 \mathrm{aB}$ \\
\hline CEN239 & $48,19 \mathrm{aA}$ & $93,88 \mathrm{bB}$ \\
\hline CEN240 & $52,24 \mathrm{aA}$ & $81,31 \mathrm{aB}$ \\
\hline CEN241 & $51,77 \mathrm{aA}$ & $85,66 \mathrm{aB}$ \\
\hline Testemunha $^{(3)}$ & $100,00 \mathrm{~b}$ & $100,00 \mathrm{~b}$ \\
\hline Média $^{(4)}$ & $49,88 \mathrm{~A}$ & $86,61 \mathrm{~B}$ \\
\hline Coeficiente de variação & $9,91 \%$ & $5,88 \%$ \\
\hline
\end{tabular}

${ }^{(1)}$ Valores seguidos pela mesma letra minúscula em cada coluna e mesma letra maiúscula em uma linha, não diferem estatisticamente, segundo o teste de Scott-Knott $(\mathrm{P} \leq 0,05) ;{ }^{(2)}$ Valores relativos a Testemunha, obtidos de colônias com 8 e 7 dias de crescimento, para os ensaios com metabólitos voláteis e não voláteis, respectivamente; ${ }^{(3)}$ Metabólitos voláteis: sem adição de disco do antagonista na placa correspondente; Metabólitos não voláteis: adicionou-se $5 \mathrm{~mL}$ de água destilada esterilizada ao BDA fundente das placas; ${ }^{(4)}$ Média geral do crescimento de colônias de $F$. oxysporum sob o efeito de metabólitos de T. harzianum (\%). 
de feijão, reduzindo em $73 \%$ a incidência do patógeno nas sementes, aos sete dias após o tratamento químico e biológico das sementes infectadas. Embora nenhum dos tratamentos biológicos tenha sido estatisticamente similar ao fungicida químico, os isolados CEN202, CEN234, CEN238, CEN240 e Trichodermil ${ }^{\circledR}$ SC foram superiores à testemunha (sementes não tratadas) no controle de $F$. oxysporum f. sp. phaseoli, reduzindo a incidência do patógeno em 48, 40, 35, 51 e $45 \%$, respectivamente, nas sementes (Tabela 3 ).

De forma similar, os tratamentos supracitados proporcionaram um percentual de plântulas normais superiores à testemunha, aos nove dias de germinação, em sementes que receberam aplicação do patógeno. Embora tenha proporcionado incidência de $37 \%$ do patógeno aos sete dias, verificou-se $73,6 \%$ de plântulas normais aos nove dias, quando as sementes infectadas foram tratadas com CEN239. Portanto, o isolado CEN239 conferiu um aumento de vigor às sementes infectadas.

Outro ponto importante a ser destacado reside na capacidade de controle biológico de patógenos de sementes pela ação de metabólitos voláteis de T. harzianum (Agüero et al., 2008). Conforme verificado in vitro, é provável que as diferenças no percentual de incidência do patógeno e de plântulas normais oriundas das sementes infectadas tenha sido causada pela ação desses metabólitos, para todos os isolados de T. harzianum. De forma análoga, Dubey et al. (2007), após selecionarem isolados de Trichoderma baseando-se em testes in vitro de cultura pareada e metabólitos voláteis e não voláteis, também verificaram o controle in vivo de $F$. oxysporum f.sp. ciceris ao realizar a microbiolização com $10^{6}$ conídios de Trichoderma spp. $10 \mathrm{~g}^{-1}$ de sementes de ervilha, semeadas em vaso com solo infestado pelo patógeno. Embora tenham empregado menor concentração do antagonista, Dubey et al. (2007) verificaram entre 21 e $30,6 \%$ de incidência de murcha nas plantas obtidas de sementes tratadas com $T$. harzianum contra 62 a $74 \%$ de incidência nas plantas obtidas de sementes sem tratamento. Tais valores foram muito próximos aos obtidos no presente trabalho, ao se avaliar a incidência nas sementes e plântulas infectadas por F. oxysporum f.sp. phaseoli. Por exemplo, CEN202, CEN234, CEN238 e CEN 240 apresentaram 24,5, $28,0,30,5$ e $23 \%$ de incidência, respectivamente, contra $47 \%$ de incidência nas plântulas da testemunha.

A incidência do patógeno em sementes não significa necessariamente comprometimento da germinação e origem de plântulas normais (França Neto \& Henning, 1984). A presença do patógeno pode estar limitada ao tegumento que, durante o processo de emergência, será deixado no substrato, sem prejuízo sanitário para as plântulas originadas (Mertz et al., 2009). O tratamento com $2 \mathrm{~mL}$ de suspensão a $2,5 \times 10^{8}$ conídios $\mathrm{mL}^{-1}$ de $T$. harzianum para cada $100 \mathrm{~g}$ de sementes sadias de feijoeiro não ocasionou sintomas de toxidez ou qualquer outro prejuízo à germinação das sementes. Três dos seis isolados (CEN238, CEN240 e CEN241), assim como o isolado comercial, proporcionaram percentuais de plântulas normais superiores às provenientes de sementes não tratadas. Por outro lado, CEN241 foi o único isolado que não apresentou efeito no controle de $F$. oxysporum f. phaseoli nas sementes. Quando foram comparadas sementes infectadas e sementes que não receberam o inóculo do patógeno, os tratamentos com os isolados CEN202 e CEN234 não proporcionaram incremento no vigor das sementes. Portanto, pode-se inferir que os dois últimos isolados são mais aptos em controlar F. oxysporum

TABELA 3 - Incidência de Fusarium oxysporum em sementes e plântulas de feijão comum 'Jalo Precoce' tratadas com isolados de Trichoderma harzianum e respectivos efeitos sobre a germinação de sementes infectadas e não infectadas pelo patógeno

\begin{tabular}{|c|c|c|c|}
\hline \multirow[t]{2}{*}{ Tratamentos $^{(1)}$} & \multirow{2}{*}{$\begin{array}{c}{\text { Incidência }(\%)^{(2)}}^{\text {Fusarium oxysporum }^{(3)}} \\
\end{array}$} & \multicolumn{2}{|c|}{ Germinação (\%) ${ }^{(2)}$} \\
\hline & & $\begin{array}{l}\text { Plântulas normais - sementes } \\
\text { infectadas por } F \text {. oxysporum }\end{array}$ & $\begin{array}{c}\text { Plântulas normais - sementes } \\
\text { sadias }^{(4)}\end{array}$ \\
\hline CEN202 & $24,5 \mathrm{~b}$ & $77,0 \mathrm{aA}$ & $84,0 \mathrm{bA}$ \\
\hline CEN234 & $28,0 \mathrm{~b}$ & $81,5 \mathrm{aA}$ & 86,6 bA \\
\hline CEN238 & $30,5 \mathrm{~b}$ & $77,5 \mathrm{aA}$ & $92,6 \mathrm{aB}$ \\
\hline CEN239 & $37,0 \mathrm{c}$ & $73,6 \mathrm{aA}$ & $87,3 \mathrm{bB}$ \\
\hline CEN240 & $23,0 \mathrm{~b}$ & $73,5 \mathrm{aA}$ & $92,6 \mathrm{aB}$ \\
\hline CEN241 & $39,0 \mathrm{c}$ & $64,0 \mathrm{bA}$ & $91,1 \mathrm{aB}$ \\
\hline Isolado comercial & $26,0 \mathrm{~b}$ & $76,0 \mathrm{aA}$ & $94,0 \mathrm{aB}$ \\
\hline Carboxina + Tiram $^{(5)}$ & $13,0 \mathrm{a}$ & $84,5 \mathrm{aA}$ & $94,5 \mathrm{aB}$ \\
\hline Testemunha $^{(6)}$ & $47,0 \mathrm{c}$ & $58,5 \mathrm{bA}$ & $88,0 \mathrm{bB}$ \\
\hline Média $^{(7)}$ & - & $74,0 \mathrm{~A}$ & $90,1 \mathrm{~B}$ \\
\hline Coeficiente de Variação & $25,43 \%$ & $7,56 \%$ & $4,94 \%$ \\
\hline
\end{tabular}

(1)Isolados de T. harzianum e isolado comercial Trichodermil ${ }^{\circledR} \mathrm{SC}$ (suspensão concentrada de T. harzianum em óleo emulsionável), empregados para o tratamento das sementes a $2 \mathrm{~mL} 100 \mathrm{~g}^{-1}$ sementes $\left(2,5 \times 10^{8}\right.$ conídios $\left.\mathrm{mL}^{-1}\right)$; ${ }^{(2)}$ Valores seguidos pela mesma letra minúscula em cada coluna e mesma letra maiúscula em uma linha, não diferem estatisticamente, segundo o teste de Scott-Knott $(\mathrm{P} \leq 0,05)$; ${ }^{(3)}$ Sementes artificialmente infectadas e infestadas com Fusarium oxysporum f.sp. phaseoli (C-25-02); ${ }^{4}$ Sementes sadias, desinfestadas em solução Hipoclorito de sódio

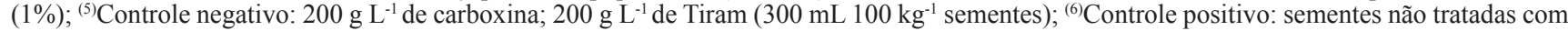
Trichoderma; ${ }^{(7)}$ Média geral do número de plântulas normais (sementes infectadas e sadias). 
em sementes de feijão do que em promover um incremento no percentual de plântulas normais oriundas de sementes sadias.

\section{Efeito de Trichoderma harzianum no crescimento de plantas de feijoeiro em casa de vegetação}

Os valores médios de comprimento da parte aérea das plantas oriundas de sementes não tratadas com Rhal S1 ${ }^{\circledR}$ em substrato tratado com T. harzianum (isolados CEN202, CEN239, CEN240 e CEN241) foram estatisticamente superiores aos demais tratamentos (Tabela 4). Na avaliação do comprimento médio das raízes das mesmas plantas, CEN239 foi superior à testemunha absoluta (sementes sem tratamento em substrato autoclavado). Opostamente, o comprimento médio das raízes de CEN238 e CEN240 foram inferiores ao da testemunha absoluta, sugerindo efeito negativo desses isolados de T. harzianum, quando aplicados na dosagem de $50 \mathrm{~mL}$ de suspensão a $10^{8}$ conídios $\mathrm{mL}^{-1}$ por vaso. Tal efeito foi bastante evidenciado no tratamento com CEN238, cuja maioria das plantas exibiu áreas necrosadas na raiz pivotante, no momento da avaliação. Embora tais efeitos negativos de Trichoderma em plantas sejam eventos raros, Carvalho et al. (2006) relataram produção de metabólitos tóxicos a coleóptilos de trigo por T. viride. Vale ressaltar, entretanto, que a maioria dos relatos encontrados na literatura refere-se à capacidade de fungos do gênero Trichoderma em promover o crescimento e a produtividade das culturas (Vinale et al., 2008).

Um isolado de T. harzianum (T-22) é comercializado em vários países como princípio ativo de inoculantes de efeito biofungicida e promotor de desenvolvimento de plantas. Harman (2000) relatou promoção de crescimento com esse isolado nas culturas de soja (Glycine max) e milho (Zea mays), além de incremento na produção de frutos de pimentão (Capsicum annum), comparativamente ao controle (plantas não tratadas com o fungo). Provavelmente, o efeito negativo verificado seja função de dose e, principalmente, de isolado, visto que, no presente trabalho, repetido duas vezes, observou-se efeito positivo com o isolado CEN239.

Quando as sementes foram tratadas com o promotor de crescimento Rhal $\mathrm{S} 1^{\circledR}$, adicionalmente ao tratamento com $T$. harzianum, não se constataram diferenças entre tratamentos, tampouco destes em relação à testemunha, no comprimento da parte aérea das plantas. Quanto ao comprimento de raízes e comprimento total de plântulas, todos os tratamentos foram inferiores à testemunha, a exceção do isolado CEN239. Rhal S1 ${ }^{\circledR}$ é um promotor de enraizamento, cujo efeito foi confirmado neste trabalho. $\mathrm{O}$ incremento médio de crescimento de raízes com esse produto foi de $24,85 \%$ (Tabela 4). De acordo com Silva et al. (2000), esse efeito pode ser atribuído às substâncias húmicas presentes na composição do produto. Entretanto, o presente trabalho mostrou que o seu emprego, simultaneamente às inoculações com Trichoderma, não é indicado.

Pode-se concluir que os seis isolados de T. harzianum testados possuem potencial como antagonistas contra F. oxysporum f.sp. phaseoli. A produção de metabólitos voláteis é um mecanismo de ação comum a todos esses isolados. Como promotor de crescimento, pode-se indicar, com base nos resultados aqui obtidos, o isolado CEN239, embora outros três isolados também tenham se revelado capazes de promover o desenvolvimento de parte aérea

TABELA 4 - Comprimento da parte aérea, da raiz e comprimento total de plantas de feijoeiro comum 'Jalo Precoce', cultivadas durante 11 dias em substrato tratado com isolados de Trichoderma harzianum

\begin{tabular}{|c|c|c|c|c|c|c|}
\hline \multirow{3}{*}{$\begin{array}{l}\text { Isolados de } \\
\text { T. harzianum }\end{array}$} & \multicolumn{6}{|c|}{ Comprimento $(\mathrm{cm})^{(2)}$} \\
\hline & \multicolumn{3}{|c|}{$\begin{array}{c}\text { Substrato tratado com Trichoderma } \\
\text { harzianum }\end{array}$} & \multicolumn{3}{|c|}{$\begin{array}{l}\text { Substrato tratado com Trichoderma } \\
\text { harzianum + sementes tratadas com } \\
\text { formulação de ácidos húmicos }{ }^{(3)}\end{array}$} \\
\hline & Parte aérea & Raízes & Total & Parte aérea & Raízes & Total \\
\hline CEN202 & $19,37 \mathrm{aA}$ & $14,58 \mathrm{bA}$ & $33,95 \mathrm{bA}$ & $19,01 \mathrm{aA}$ & $13,61 \mathrm{bA}$ & $32,62 \mathrm{bA}$ \\
\hline CEN234 & $17,96 \mathrm{bA}$ & $13,35 \mathrm{bA}$ & $31,31 \mathrm{cA}$ & $19,29 \mathrm{aB}$ & $11,94 \mathrm{cA}$ & $31,23 \mathrm{cA}$ \\
\hline CEN238 & $18,03 \mathrm{bA}$ & $9,81 \mathrm{cA}$ & $27,84 \mathrm{dA}$ & $18,78 \mathrm{aA}$ & $9,67 \mathrm{dA}$ & $28,45 \mathrm{dA}$ \\
\hline CEN239 & $19,61 \mathrm{aA}$ & $17,81 \mathrm{aA}$ & $37,43 \mathrm{aA}$ & $19,00 \mathrm{aA}$ & $16,97 \mathrm{aA}$ & $35,97 \mathrm{aA}$ \\
\hline CEN240 & $19,46 \mathrm{aB}$ & $10,93 \mathrm{cA}$ & $30,39 \mathrm{cA}$ & $18,16 \mathrm{aA}$ & $14,26 \mathrm{bB}$ & $32,42 \mathrm{bB}$ \\
\hline CEN241 & $19,37 \mathrm{aA}$ & $14,55 \mathrm{bA}$ & $33,92 \mathrm{bA}$ & $18,60 \mathrm{aA}$ & $15,39 \mathrm{bA}$ & $33,91 \mathrm{bA}$ \\
\hline Isolado comercial & $18,45 \mathrm{bA}$ & $15,44 \mathrm{bA}$ & $33,89 \mathrm{bA}$ & $18,44 \mathrm{aA}$ & $14,59 \mathrm{bA}$ & $33,03 \mathrm{bA}$ \\
\hline Testemunha $^{(4)}$ & $18,55 \mathrm{bA}$ & $13,60 \mathrm{bA}$ & $32,15 \mathrm{cA}$ & $18,61 \mathrm{aA}$ & $16,98 \mathrm{aB}$ & $35,59 \mathrm{aB}$ \\
\hline $\operatorname{Média}^{(5)}$ & $18,85 \mathrm{~A}$ & $13,76 \mathrm{~A}$ & $32,61 \mathrm{~A}$ & $18,73 \mathrm{~A}$ & $14,17 \mathrm{~A}$ & $32,91 \mathrm{~A}$ \\
\hline Coeficiente de variação & $5,21 \%$ & $16,55 \%$ & $7,35 \%$ & $5,92 \%$ & $14,67 \%$ & $7,50 \%$ \\
\hline
\end{tabular}

${ }^{(1)}$ Substrato tratado com $50 \mathrm{~mL}$ vaso ${ }^{-1}$ de suspensão de esporos dos isolados de T. harzianum e isolado comercial Trichodermil ${ }^{\circledR} \mathrm{SC}$ (suspensão concentrada de T. harzianum em óleo emulsionável) a $10^{8}$ conídios $\mathrm{mL}^{-1}$; (2) Valores seguidos pela mesma letra minúscula na coluna e mesma letra maiúscula nas linhas, não diferem estatisticamente, segundo o teste de Scott-Knott $(\mathrm{P} \leq 0,05) ;{ }^{(3)} \mathrm{Rhal} \mathrm{S1}{ }^{\circledR}(18 \%$ de ácidos húmicos; $1,5 \%$ de ácidos fúlvicos) a $600 \mathrm{~mL} 100 \mathrm{~kg}^{-1}$ sementes; ${ }^{\left({ }^{4}\right)}$ Testemunha: sementes em substrato sem adição de Trichoderma; ${ }^{(5)}$ Média geral do comprimento da parte aérea, das raízes e comprimento total das plantas cultivadas em substrato tratado com os isolados de T. harzianum (com e sem Rhal S1 ${ }^{\mathbb{E}}$ no tratamento das sementes). 
de feijoeiro. Por outro lado, é importante que os estudos com esses isolados de T. harzianum, associados ou não com reguladores de crescimento, sejam continuados para observação desses efeitos em outras culturas.

\section{AGRADECIMENTOS}

Ao Conselho Nacional de Desenvolvimento Científico e Tecnológico - CNPq e à Fundação de Apoio à Pesquisa do Distrito Federal FAPDF, pela concessão de bolsas e auxílio financeiro.

\section{REFERÊNCIAS BIBLIOGRÁFICAS}

Agüero LEM, Alvarado R, Martínez A, Dorta B (2008) Inhibition of Aspergillus flavus growth and aflatoxin b1 production in stored maize grains exposed to volatile compounds of Trichoderma harzianum Rifai. Interciência 33:219-222.

Ávila ZR, Carvalho SS, Braúna LM, Gomes DMPA, Silva MCF, Mello SCM (2005) Seleção de isolados de Trichoderma spp. antagônicos a Sclerotium rolfsii e Sclerotinia sclerotiorum. Brasília DF. Embrapa Recursos Genéticos. Boletim Técnico n ${ }^{\circ}$ 177.

Bell DK, Wells HD, Markham CR (1982) In vitro antagonism of Trichoderma species against six fungal plant pathogens. Phytopathology 72:379-382.

Benítez T, Ricón AM, Limón MC, Codón AC (2004) Biocontrol mechanisms of Trichoderma strains. International Microbiology 7:249-260.

Brasil (2009) Regras Para Análise de Sementes. Brasília DF. Ministério da Agricultura, Pecuária e Abastecimento. Secretaria de Defesa Agropecuária.

Carvalho DDC, Oliveira DF, Campos VP, Pasqual M, Guimarães RM, Corrêa RSB (2006) Avaliação da capacidade de produzir fitotoxinas in vitro por parte de fungos com propriedades antagônicas a nematóides. Ciência e Agrotecnologia 30:12301235.

Corrêa BO, Moura AB, Denardin ND, Soares VN, Schäfer JT, Ludwig J (2008) Influência da microbiolização de sementes de feijão sobre a transmissão de Colletotrichum lindemuthianum Sacc. \& Magn. Revista Brasileira de Sementes 30:156-163.

Costa MLN, Machado JC, Guimarães RM, Pozza EA, Oride D (2003) Inoculação de Fusarium oxysporum f.sp. phaseoli em sementes de feijoeiro através de restrição hídrica. Ciência e Agrotecnologia 27:1023-1030

Dennis C, Webster J (1971) Antagonistic properties of species- groups of Trichoderma, III Hyphal interactions. Transactions British Mycological Society 57:363-369.

Dubey SC, Suresh M, Singh B (2007) Evaluation of Trichoderma species against Fusarium oxysporum f.sp. ciceris for integrated management of chickpea wilt. Biological Control 40:118-127.

Ferreira DF (2000) Análises estatísticas por meio do Sisvar para Windows versão 4.0. In: Reunião Anual da Região Brasileira da Sociedade Internacional de Biometria, 45. São Carlos: UFSCar. pp. 255-258.

França-Neto JB, Henning AA (1984) Qualidade fisiológica e sanitária de sementes de soja. Londrina PR. Embrapa Soja.

Harman GE, Howell CR, Viterbo A, Chet I, Lorito M (2004) Trichoderma species - opportunistic, avirulent plant symbionts. Nature Reviews Microbiology 2:43-56.

Harman GE (2000). Myth and dogmas of biocontrol changes in perceptions derived from research on Trichoderma harzianum T22. Plant Disease 84:377-393.

Machado JC, Oliveira JA, Vieira MGGC, Alves MC (2001) Inoculação artificial de sementes de soja por fungos, utilizando solução de manitol. Revista Brasileira de Sementes 23:95-101.

Martins-Corder MP, Melo IS (1998) Antagonismo in vitro de Trichoderma spp. a Verticillium dahliae Kleb. Scientia Agricola 55:1-7.

Mello SCM, Ávila ZR, Braúna LM, Pádua A R, Gomes D (2007) Cepas de Trichoderma spp. para el control biológico de Sclerotium rolfsii. Fitosanidad 11:3-9.

Mertz LM, Henning FA, Zimmer PD (2009). Bioprotetores e fungicidas químicos no tratamento de sementes de soja. Ciência Rural 39:13-18.

Paula Júnior TJ, Vieira RF, Teixeira H, Coelho RR, Carneiro JES, Andrade MJB, Rezende AM (2008) Informações técnicas para o cultivo do feijoeiro-comum na região central brasileira: 20072009. Viçosa MG. EPAMIG-CTZM.

Silva GC, Gomes DP, Kronka AZ, Moraes MH (2008) Qualidade fisiológica e sanitária de sementes de feijoeiro (Phaseolus vulgaris L.) provenientes do estado de Goiás. Semina Ciências Agrárias (Londrina) 29:29-34.

Silva RM, Jablonski A, Siewerdt L, Silveira Júnior P (2000) Desenvolvimento das raízes do milheto (Pennisetum glaucum L.) cultivado com adição de substâncias húmicas. Revista Brasileira de Agrociência 6:152-156.

Taiz L, Zeiger E (2006) Plant Physiology. 4. ed. Sunderland. Sinauer Associates, Inc. Publishers.

Vinale F, Sivasithamparam K, Ghisalberti EL, Marra R, Woo SL, Lorito M (2008) Trichoderma-plant-pathogen interactions. Soil Biology \& Biochemistry 40:1-10. 